\title{
Experiences of occupational violence in Australian urban general practice: a cross-sectional study of GPs
}

\author{
Parker J Magin, Jon Adams, David W Sibbritt, Elyssa Joy and Malcolm C Ireland
}

W orkplace violence has been recognised as a significant problem in general practice. ${ }^{1,2} \mathrm{~A}$ number of studies, especially questionnaire-based retrospective studies from the United Kingdom, have established a relatively high prevalence of violence in the work experiences of general practitioners and have characterised many aspects of the nature of such violence. $^{3-8}$ Violence in this context encompasses not only physical injury to the GP but also verbal abuse, threatening behaviour and sexual harassment, violence directed towards general practice staff, and the damaging of property. In these studies, verbal abuse has been consistently the most prevalent type of violence experienced by GPs, but there have also been consistent findings of more serious types of violence - assault and stalking - albeit at low prevalence.

Studies in rural Australia ${ }^{9-11}$ have demonstrated that occupational violence is also a significant problem for Australian rural GPs. However, there has been a lack of research in Australian urban general practice on this important issue. Furthermore, previous studies of violence in general practice have employed univariate analysis only. Given the likely clustering of socioeconomic, mentalhealth, and drug- and alcohol-related problems (factors associated with violence in these earlier studies), multivariate analysis is especially indicated for studies in this area. In response, we employ multivariate analyses in reporting on prevalence and characteristics of violence in Australian urban general practice and how these correlate with GP demographics.

\section{METHODS}

\section{Survey}

Following a qualitative study involving GP focus groups conducted in $2003,{ }^{12}$ a 60 item questionnaire was constructed and

\section{ABSTRACT}

Objective: To establish the prevalence and characteristics of occupational violence in Australian urban general practice, and examine practitioner correlates of violence.

Design, setting and participants: Cross-sectional questionnaire survey mailed to all members $(n=1085)$ of three urban divisions of general practice in New South Wales in August and September 2004. The three divisions were chosen to provide a range of socioeconomic status (SES) demographics.

Main outcome measures: Occupational violence towards general practitioners during the previous 12 months.

Results: 528 GPs returned questionnaires (49\% response rate). Of these, $63.7 \%$ had experienced violence in the previous year. The most common forms of violence were "low level" violence - verbal abuse (42.1\%), property damage/theft (28.6\%) and threats (23.1\%). A smaller proportion of GPs had experienced "high level" violence, such as sexual harassment (9.3\%) and physical abuse (2.7\%). On univariate analysis, violence was significantly more likely towards female GPs $(P<0.001)$, less experienced GPs $(P=0.003)$ and GPs working in a lower SES status area $(P<0.001)$, and among practice populations encompassing greater social disadvantage $(P=0.006)$, mental health problems $(P<0.001)$, and drug- and alcohol-related problems $(P<0.001)$. Experience of violence was greater for younger GPs $(P=0.005)$ and those providing after-hours care $(P=0.033$ for after-hours home visits). On multivariate analysis, a significant association persisted between high level violence and lower SES area (odds ratio [OR], 2.86), being female $(\mathrm{OR}, 5.87)$, having practice populations with more drug-related problems (OR, 5.77), and providing home visits during business hours (OR, 4.76). More experienced GPs encountered less violence $(\mathrm{OR}, 0.77)$ for every additional 5 years of practice.

Conclusion: Occupational violence is a considerable problem in Australian urban general practice. Formal education programs in preventing and managing violence would be appropriate for GPs and doctors-in-training.

MJA 2005; 183: 352-356

mailed (with a single follow-up mail-out) to all 1085 members of three urban divisions of general practice in New South Wales in August and September 2004. The three divisions were chosen to provide a range of socioeconomic status (SES) demographics within Rural Remote and Metropolitan Areas (RRMA) $)^{13}$ classifications 1 and 2 (incorporating capital cities and other metropolitan centres). The questionnaire elicited demographic data on the GPs and their practice (including self-assessed levels of social disadvantage, drug- and alcohol-

Discipline of General Practice, University of Newcastle, Callaghan, NSW.

Parker J Magin, MB BS, Senior Lecturer; Elyssa Joy, BA, Research Assistant; Malcolm C Ireland, MB BS, Senior Lecturer.

Centre for Clinical Epidemiology and Biostatistics, University of Newcastle, Callaghan, NSW. Jon Adams, PhD, Senior Lecturer; David W Sibbritt, PhD, Senior Lecturer.

Reprints will not be available from the authors. Correspondence: Dr Parker J Magin, Discipline of General Practice, University of Newcastle, University Drive, Callaghan, NSW 2308.

parker.magin@newcastle.edu.au

related illness and psychiatric illness among their patients), experiences of violence, and education and training related to violence.

Levels of violence were classified as "high level" violence (physical abuse, sexual abuse, stalking, or sexual harassment) or "low level" violence (verbal abuse, property damage/theft, threats, or slander). Slander was defined as false and malicious accusations related to the GP's professional role made by a patient or patient's friend or family member.

\section{Statistical analysis}

The prevalence of the types and levels of violence experienced by GPs in the past 12 months were reported. Bivariate analyses using $\chi^{2}$ tests or two-sample $t$ tests were used to compare the distribution of demographic and practice-related factors in relation to the levels of violence experienced by 
GPs in the past 12 months. Multivariate polytomous logistic regression was used to compare GPs who had experienced low or high level violence in the past 12 months with those who had not. (Polytomous logistic regression is similar to logistic regression except that the dependent variable can take on more than two values.)

A parsimonious model was determined using a stepwise backward elimination method based on the likelihood-ratio test using a significance level of 0.05. All analyses were conducted using Stata version 8.2 software (Stata Corporation, College Station, Tex, USA).

\section{Ethical approval}

Our study was approved by the Human Research Ethics Committee of the University of Newcastle.

\section{Characteristics of urban general practitioners in our sample compared with national estimates

\begin{tabular}{lcc} 
Characteristic & $\begin{array}{c}\text { Our sample } \\
(n=528)\end{array}$ & $\begin{array}{c}\text { National } \\
\text { statistics* }\end{array}$ \\
\hline Sex & $266(50.4 \%)$ & $10831(62.0 \%)$ \\
Male & $262(49.6 \%)$ & $6651(38.0 \%)$ \\
Age (years) & & \\
$<35$ & $24(4.5 \%)$ & $1533(8.8 \%)$ \\
$35-44$ & $113(21.4 \%)$ & $4851(27.7 \%)$ \\
$45-54$ & $213(40.3 \%)$ & $5532(32.0 \%)$ \\
$\geqslant 55$ & $175(33.1 \%)$ & $5566(31.8 \%)$ \\
Not known & $3(0.6 \%)$ & \\
\hline
\end{tabular}

* Source: Australian Government Department of Health and Ageing general practitioner statistics 2003-2004.

\section{Number of general practitioners experiencing various types of violence in the previous 12 months $(n=528)$ *}

\begin{tabular}{lccc} 
Type of violence & $\begin{array}{c}\text { Violence } \\
\text { experienced }\end{array}$ & $\begin{array}{c}\text { No violence } \\
\text { experienced }\end{array}$ & $\begin{array}{c}\text { Proportion of GPs experiencing } \\
\text { violence (95\% CI) }\end{array}$ \\
\hline Verbal abuse & 222 & 305 & $42.1 \%(37.8 \%-46.3 \%)$ \\
Property damage/theft & 151 & 374 & $28.6 \%(24.7 \%-32.5 \%)$ \\
Threats & 122 & 403 & $23.1 \%(19.5 \%-26.7 \%)$ \\
Slander & 90 & 428 & $17.1 \%(13.8 \%-20.3 \%)$ \\
Sexual harassment & 49 & 475 & $9.3 \%(6.8 \%-11.8 \%)$ \\
Stalking & 16 & 509 & $3.0 \%(1.6 \%-4.5 \%)$ \\
Physical abuse & 14 & 511 & $2.7 \%(1.3 \%-4.0 \%)$ \\
Sexual abuse & 1 & 524 & $0.2 \%(0.0 \%-0.6 \%)$ \\
\hline
\end{tabular}

* Rows do not add up to 528 because some respondents did not answer all questions.
A total of 528 replies was received (response rate 49\%). Response rates for the individual divisions were 50\% (high SES capital city division), 36\% (low SES capital city division) and 54\% (mixed SES non-capital city division). The mean age of respondents was 51.3 years (SD, 10.7 years), and $50 \%$ of respondents were women. (For comparison with national data see Box 1 ).

The majority (63.7\%) of GPs surveyed had been subjected to some form of violence within the previous 12 months. The most common forms of violence were verbal abuse $(42.1 \%)$, property damage or theft $(28.6 \%)$, threats $(23.1 \%)$, and slander (17.1\%) (Box 2). Sixty-eight GPs (12.9\%) experienced high level violence, while 263 GPs (49.8\%) experienced only low level violence (Box 3).

\section{Univariate analysis}

Demographic and practice-related factors compared across the levels of violence experienced by GPs in the past 12 months are shown in Box 4. In terms of statistically significant GP demographic factors, GPs reporting high level violence were more likely to be female, to be younger in age, and to have less years of experience as a GP. In terms of statistically significant practicerelated factors, GPs experiencing both low and high levels of violence were more likely to report having a higher than average number of patients who were socially disadvantaged and/or had mental-health or drugrelated problems. In addition, GPs were more likely to experience violence if they worked longer hours per week, conducted home visits after hours, worked after hours in a cooperative clinic, or worked in the low SES division.

\section{RESULTS}

\section{Frequency of the levels of violence experienced by general practitioners in the previous 12 months*}

\begin{tabular}{lcc}
$\begin{array}{l}\text { Violence } \\
\text { level }\end{array}$ & $\begin{array}{c}\text { Number } \\
\text { of GPs }\end{array}$ & $\begin{array}{c}\text { Proportion of GPs } \\
(95 \% \mathrm{Cl})\end{array}$ \\
\hline None & 196 & $37.1 \%(33.0 \%-41.2 \%)$ \\
Low level & 263 & $49.8 \%(45.5 \%-54.1 \%)$ \\
High level & 68 & $12.9 \%(10.0 \%-15.7 \%)$ \\
\hline
\end{tabular}

*One respondent did not answer any question relating to violence.

\section{Multivariate analysis}

Multivariate polytomous logistic regression modelling was used to compare GPs who had experienced low or high level violence in the past 12 months with those who had not (Box 5). Comparison between the univariate and multivariate analyses did not reveal any evidence of confounding.

After multivariate analysis, GP demographic factors that remained significant were sex and number of years worked as a GP. Female GPs were more likely to experience both low and high level violence than males, while having more years' experience as a GP was associated with a reduction in both low and high level violence. For every 5 years worked as a GP, the decline in likelihood of experiencing violence was 0.9 (for low level violence) and 0.8 (for high level violence).

Practice-related factors that remained significantly associated with low level violence were having a higher than average proportion of patients with mental-health or drug-related problems, working after hours in a cooperative clinic and working 20-29 hours or $\geqslant 40$ hours per week. Factors significantly associated with high level violence were working in a low SES division, having a higher than average proportion of patients with drug-related problems, working 20-29 hours or $\geqslant 40$ hours per week, and making home visits during business hours.

The study participants were also questioned about workplace violence education or training. Most GPs (80\%) had not received any education or training related to workplace violence. Of those who had received some form of training, 15\% were prompted by a personal experience or an episode of violence in general practice. Sixty per cent of the GPs surveyed indicated that they would benefit from further education or training in managing violence. 


\begin{tabular}{|c|c|c|c|c|c|c|c|c|c|}
\hline \multicolumn{10}{|c|}{$\begin{array}{l}4 \text { Association of demographic and practice-related } \\
\text { levels of violence over the previous } 12 \text { months }{ }^{\star}\end{array}$} \\
\hline \multirow[b]{2}{*}{ Factor } & \multicolumn{3}{|c|}{ Level of violence } & \multirow[b]{2}{*}{$P$} & \multirow[b]{2}{*}{ Factor } & \multicolumn{3}{|c|}{ Level of violence } & \multirow[b]{2}{*}{$P$} \\
\hline & $\begin{array}{c}\text { None } \\
(n=196)\end{array}$ & $\begin{array}{l}\text { Low level } \\
(n=263)\end{array}$ & $\begin{array}{l}\text { High level } \\
(n=68)\end{array}$ & & & $\begin{array}{c}\text { None } \\
(n=196)\end{array}$ & $\begin{array}{l}\text { Low level } \\
(n=263)\end{array}$ & $\begin{array}{c}\text { High level } \\
(n=68)\end{array}$ & \\
\hline \multicolumn{4}{|l|}{ Sex of GP } & $<0.001$ & \multicolumn{4}{|c|}{ Proportion of patients with alcohol-related problems ${ }^{\dagger}$} & $<0.001$ \\
\hline Female & $45 \%$ & $46 \%$ & $75 \%$ & & Less than other practices & $42 \%$ & $25 \%$ & $40 \%$ & \\
\hline Male & $55 \%$ & $54 \%$ & $25 \%$ & & Same as other practices & $55 \%$ & $67 \%$ & $50 \%$ & \\
\hline \multicolumn{4}{|l|}{ Country qualified } & 0.829 & More than other practices & $3 \%$ & $8 \%$ & $10 \%$ & \\
\hline Australia & $76 \%$ & $76 \%$ & $80 \%$ & & \multicolumn{5}{|c|}{ Proportion of patients with drug-related problems ${ }^{\dagger}$} \\
\hline Overseas & $24 \%$ & $24 \%$ & $20 \%$ & & Less than other practices & $69 \%$ & $54 \%$ & $53 \%$ & $<0.001$ \\
\hline \multicolumn{4}{|l|}{ Main type of work } & 0.402 & Same as other practices & $28 \%$ & $33 \%$ & $32 \%$ & \\
\hline Sole practitioner & $22 \%$ & $22 \%$ & $17 \%$ & & More than other practices & $3 \%$ & $13 \%$ & $15 \%$ & \\
\hline Partner & $20 \%$ & $25 \%$ & $15 \%$ & & \multicolumn{4}{|l|}{ Number of GPs in practice } & 0.913 \\
\hline Associate & $27 \%$ & $26 \%$ & $36 \%$ & & 1 & $20 \%$ & $18 \%$ & $15 \%$ & \\
\hline Assistant & $19 \%$ & $14 \%$ & $16 \%$ & & 2 & $16 \%$ & $15 \%$ & $16 \%$ & \\
\hline Other & $12 \%$ & $13 \%$ & $16 \%$ & & $3-4$ & $21 \%$ & $24 \%$ & $28 \%$ & \\
\hline \multicolumn{4}{|l|}{ Billing practice } & 0.487 & $\geqslant 5$ & $43 \%$ & $43 \%$ & $41 \%$ & \\
\hline Totally private & $6 \%$ & $5 \%$ & $10 \%$ & & \multicolumn{4}{|l|}{ Hours worked per week } & 0.001 \\
\hline Totally bulk-billing & $19 \%$ & $19 \%$ & $21 \%$ & & $<20$ & $23 \%$ & $12 \%$ & $13 \%$ & \\
\hline Mixed private and bulk-billing & $75 \%$ & $76 \%$ & $69 \%$ & & $20-29$ & $13 \%$ & $18 \%$ & $28 \%$ & \\
\hline \multicolumn{4}{|l|}{ Type of practice } & 0.841 & 30-39 & $32 \%$ & $26 \%$ & $21 \%$ & \\
\hline Traditional & $87 \%$ & $89 \%$ & $87 \%$ & & $\geqslant 40$ & $32 \%$ & $44 \%$ & $38 \%$ & \\
\hline Corporate & $7 \%$ & $7 \%$ & $6 \%$ & & \multicolumn{5}{|c|}{ Type of visit in which violence experienced } \\
\hline Other & $6 \%$ & $4 \%$ & $7 \%$ & & $\begin{array}{l}\text { Home visits during } \\
\text { business hours }\end{array}$ & $85 \%$ & $88 \%$ & $93 \%$ & 0.268 \\
\hline \multicolumn{4}{|c|}{ Proportion of socially disadvantaged patients ${ }^{\dagger}$} & 0.006 & Home visits after hours & $58 \%$ & $69 \%$ & $71 \%$ & 0.033 \\
\hline Less than other practices & $51 \%$ & $37 \%$ & $33 \%$ & & Private surgery after hours & $32 \%$ & $42 \%$ & $31 \%$ & 0.050 \\
\hline Same as other practices & $37 \%$ & $41 \%$ & $44 \%$ & & Cooperative clinic after hours & $26 \%$ & $41 \%$ & $18 \%$ & $<0.001$ \\
\hline $\begin{array}{l}\text { More than other } \\
\text { practices }\end{array}$ & $12 \%$ & $22 \%$ & $23 \%$ & & \multicolumn{4}{|l|}{ Socioeconomic division } & $<0.001$ \\
\hline \multicolumn{4}{|c|}{ Proportion of patients with mental health problems ${ }^{\dagger}$} & $<0.001$ & High SES & $55 \%$ & $42 \%$ & $43 \%$ & \\
\hline Less than other practices & $30 \%$ & $11 \%$ & $20 \%$ & & Mixed SES & $32 \%$ & $46 \%$ & $30 \%$ & \\
\hline Same as other practices & $62 \%$ & $68 \%$ & $65 \%$ & & Low SES & $13 \%$ & $12 \%$ & $27 \%$ & \\
\hline \multirow[t]{2}{*}{$\begin{array}{l}\text { More than other } \\
\text { practices }\end{array}$} & $8 \%$ & $21 \%$ & $15 \%$ & & $\begin{array}{l}\text { Mean age (SD) of } \\
\text { GPs (years) }\end{array}$ & $\begin{array}{c}53.2 \\
(11.9)\end{array}$ & $\begin{array}{c}51.1 \\
(10.5)\end{array}$ & $\begin{array}{l}48.3 \\
(10.8)\end{array}$ & 0.005 \\
\hline & & & & & $\begin{array}{l}\text { Mean number of years } \\
\text { (SD) working as a GP }\end{array}$ & $\begin{array}{l}25.0 \\
(18.1)\end{array}$ & $\begin{array}{c}22.4 \\
(15.7)\end{array}$ & $\begin{array}{l}17.2 \\
(9.6)\end{array}$ & 0.003 \\
\hline
\end{tabular}

* Figures represent proportion of GPs, except where otherwise specified. † Self-assessed comparison with other general practices.

\section{DISCUSSION}

To our knowledge, this is the first formal study of prevalence and characteristics of occupational violence in Australian urban general practice. Our finding that $63.7 \%$ of GPs had experienced at least one episode of violence over the previous 12 months can be compared with a 12-month prevalence of violence of $44 \%$ and $48 \%$, respectively, in previous $\mathrm{UK}^{3}$ and rural Australian ${ }^{11}$ general practice studies. The high prevalence of verbal abuse and low (though still worrying) prevalence of stalking, physical abuse and sexual abuse were also in keeping with these and other previous studies. $6,9,10$ Slander directed at GPs was a relatively frequent occurrence. This form of violence has not been elicited in previous studies, and the implications for GPs, whose role encompasses close attachments to (and respect within) their communities, may be significant.

Our results suggest that female GPs were more likely than males to experience high and low level violence, although after multivariate analysis significance persisted only for high level violence. This finding is in 


\begin{tabular}{|c|c|c|}
\hline \multicolumn{3}{|c|}{$\begin{array}{l}5 \text { Results of multivariate polytomous logistic regression analysis comparing } \\
\text { general practitioners who experienced low or high level violence in the } \\
\text { previous } 12 \text { months with those who did not experience violence }\end{array}$} \\
\hline & $\begin{array}{l}\text { Low level violence com- } \\
\text { pared with no violence }\end{array}$ & $\begin{array}{l}\text { High level violence com- } \\
\text { pared with no violence }\end{array}$ \\
\hline Factor & OR $(95 \% \mathrm{Cl})$ & OR $(95 \% \mathrm{Cl})$ \\
\hline \multicolumn{3}{|l|}{ Division of general practice } \\
\hline Mixed SES & 1.00 & 1.00 \\
\hline Low SES & $0.95(0.43-2.10)$ & $2.86(1.00-8.43)$ \\
\hline High SES & $0.81(0.46-1.43)$ & $0.79(0.33-1.91)$ \\
\hline \multicolumn{3}{|l|}{ Sex of GP } \\
\hline Male & 1.00 & 1.00 \\
\hline Female & $1.27(0.77-2.10)$ & $5.87(2.61-13.17)$ \\
\hline \multicolumn{3}{|c|}{ Proportion of patients with mental health problems* } \\
\hline Less than other practices & 1.00 & 1.00 \\
\hline Same as other practices & $2.68(1.52-4.72)$ & $0.99(0.43-2.27)$ \\
\hline More than other practices & $4.49(1.94-10.41)$ & $0.97(0.29-3.21)$ \\
\hline \multicolumn{3}{|c|}{ Proportion of patients with drug-related problems* } \\
\hline Less than other practices & 1.00 & 1.00 \\
\hline Same as other practices & $1.05(0.65-1.71)$ & $1.74(0.82-3.70)$ \\
\hline More than other practices & $2.41(0.88-6.61)$ & $5.77(1.56-21.30)$ \\
\hline \multicolumn{3}{|l|}{ Hours worked per week } \\
\hline$<20$ & 1.00 & 1.00 \\
\hline $20-29$ & $3.24(1.56-6.73)$ & $4.59(1.65-12.78)$ \\
\hline $30-39$ & $1.74(0.93-3.29)$ & $1.31(0.48-3.60)$ \\
\hline$\geqslant 40$ & $3.37(1.73-6.59)$ & $6.26(2.16-18.10)$ \\
\hline \multicolumn{3}{|c|}{ Home visits conducted during business hours } \\
\hline No & 1.00 & 1.00 \\
\hline Yes & $0.99(0.53-1.85)$ & $4.76(1.49-14.29)$ \\
\hline \multicolumn{3}{|c|}{ Working after hours in a cooperative clinic } \\
\hline No & 1.00 & 1.00 \\
\hline Yes & $1.54(0.87-2.70)$ & $0.55(0.21-1.39)$ \\
\hline \multicolumn{3}{|l|}{ Years worked as a GP } \\
\hline Each 5-year increment & $0.91(0.82-1.02)$ & $0.77(0.66-0.90)$ \\
\hline
\end{tabular}

contrast with a UK study ${ }^{3}$ showing that male GPs experienced a higher 12-month prevalence of violence than female GPs. In an Australian rural study, ${ }^{10}$ the 12 -month prevalence of what we have characterised as "low level" violence was higher in male GPs, but "high level" violence was more common in female GPs. These discrepant findings may arise from the fact that both our study and the rural Australian study, unlike the UK study, specifically elicited sexual harassment as a form of violence.

In our study, the likelihood of having experienced violence during the previous 12 months declined with years of experience as a GP. Previous studies have not examined this aspect of general practice violence. It is possible that this finding may be attributable to the acquisition of greater interpersonal skills and patient-management techniques with longer experience as a GP, and the likely older age and greater stability of the experienced GP's patient demographic. Thus, the patients of experienced GPs are likely to be less prone to violence, and it is reasonable to expect such practitioners would have more expertise in "defusing" potentially violent situations.
We found that GPs who perceive their practice to include more patients with mental-health and drug-related problems experience more violence. This is in keeping with both quantitative and qualitative studies from the United Kingdom ${ }^{3-8,14,15}$ and Australia, ${ }^{10,11}$ which have found a significant role for psychiatric and drug-related illness in precipitating individual violent incidents in general practice.

Our study also found that GPs who rate their practice as having greater than average social disadvantage are, on univariate analysis, at greater risk of violence. This is consistent with previous research finding an association of verbal abuse of GP receptionists and practice deprivation score ${ }^{16}$ and with the qualitative perceptions of GPs. ${ }^{12,17}$ This effect was, however, no longer apparent on multivariate analysis (though the greater risk of violence in the division characterised as being of low SES persisted).

A factor to be considered here is the "clustering" of risk factors that dominated risk stratification assessments of violence by GPS in the earlier qualitative phase of our study. This suggests that social disadvantage may be a marker of mental-health or drug- and alcohol-related problems, which then precipitate episodes of violence. Similarly, "clustering" of risk factors examined in univariate analysis could be a factor in the association between mental-health problems and high level (though not low level) violence failing to persist on multivariate analysis.

To further elucidate the role of social disadvantage and mental health as independent risk factors, data on individual incidents of violence will need to be examined, rather than relying on summary assessments of practice profile and recall of violence by practitioners.

It is also difficult to interpret the greater experience of violence of GPs who do home visits or who work in after-hours cooperative clinics without examining where episodes of violence involving the individual GP occurred.

The perception from other studies that violence is more prevalent in larger practices $^{18}$ was not supported by our findings, which were consistent with those of the qualitative phase of our study. ${ }^{12}$

A strength of our study was the use of multivariate analysis to allow a more refined examination of the nature of general practice violence than previous studies, which have employed univariate analysis only.

A limitation of our study was the fairly low response rate, especially from GPs in the 
low SES division. The overall response rate of $49 \%$, while not high, is comparable with that of previous studies (range, 30\%-80\%; median, 61\%) $)^{3,5-8,10,11}$ Though conducted in only three urban divisions of general practice, these divisions were chosen to be broadly representative of Australian urban general practice demographics. Nevertheless, the demographics of the GPs in the study compared with national statistics (being somewhat older and with a higher proportion of males) should be considered in generalising our results. Furthermore, the poorer response rate in the low SES division, together with the finding of greater likelihood of experiencing violence in the low SES division, suggests our study may have underestimated the prevalence of violence overall.

Other limitations of our study, in common with previous studies, were the selfassessment by GPs of the demographic profile of their practices and the possible recall bias inherent in retrospective collection of data on such an emotive topic. Prospective studies with contemporaneous reporting of occurrence and characteristics of episodes of violence are much needed.

Nevertheless, our results have established that occupational violence is a significant problem in Australian urban general practice. Given our finding that women are more likely to experience high levels of violence, and in view of the increasing number of women in Australian general practice, ${ }^{19}$ violence is likely to be an increasing problem.

In spite of the occupational health and health-service delivery implications of violence against GPs, it is noteworthy that Australia has no systematic response to occupational violence in general practice, unlike the "zero tolerance" approach promoted by the UK National Health Service. ${ }^{17}$

Lastly, given the frequency of violence directed towards GPs, the restrictions of practice in response to violence and the implications these have for access to primary health care, ${ }^{12,20}$ it is somewhat disturbing that $80 \%$ of GPs had not had any education or training in dealing with workplace violence. Giving GPs formal education and training in dealing with violence is thus of some urgency, and our results provide an evidence base for such programs. An implication of the finding that violence is more likely for less experienced GPs may be that medical students and general practice registrars should be the primary target for education in violence prevention and management.

\section{ACKNOWLEDGEMENT}

Our study was supported by a National Health and Medical Research Council grant.

\section{COMPETING INTERESTS}

None identified.

\section{REFERENCES}

1 Wright NM, Dixon CA, Tompkins CN. Managing violence in primary care: an evidencebased approach. Br J Gen Pract 2003; 53: 557562.

2 Clode D. The conspiracy of silence: emotional health among medical practitioners. Melbourne: Royal Australian College of General Practitioners, 2004.

3 Health and Policy Economic Research Unit, British Medical Association. Violence at work: the experience of GPs in Northern Ireland. London: British Medical Association, 2003. Available at: http://www.bma.org.uk/ap.nsf/ Content/violenceNI/\$file/ViolenceNI.pdf (accessed Sep 2005)

4 General practitioners - violence against general practitioners and their staff. London: British Medical Association, 2003.

5 Hobbs FD. Violence in general practice: a survey of general practitioners' views. BMJ 1991; 302: 329-332.

6 Elston MA, Gabe G, Denney D, et al. Violence against doctors: a medical(ised) problem? The case of National Health Service general practitioners. Sociol Health IIIn 2002; 24: 575-598.

7 Myerson S. Violence to general practitioners and fear of violence. Fam Pract 1991; 8: 145147.

8 D'Urso P, Hobbs R. Aggression and the general practitioner. BMJ 1989; 298: 97-98.

9 Tolhurst H, Talbot J, Baker L, et al. Rural general practitioner apprehension about work related violence in Australia. Aust J Rural Health 2003; 11: 237-241.

10 Tolhurst H, Baker L, Murray G, et al. Rural general practitioner experience of work-related violence in Australia. Aust J Rural Health 2003; 11: 231-236.

11 Alexander C, Fraser J. Occupational violence in an Australian healthcare setting: implications for managers. J Healthc Manag 2004; 49: 377392.

12 Magin P, Adams J, Ireland M, et al. After hours care: a qualitative study of GPs' perceptions of risk of violence and effect on service provision. Aust Fam Physician 2005; 34: 91-92.

13 Department of Primary Industries and Department of Human Services and Health. Rural, Remote and Metropolitan Areas Classification. Canberra: AGPS, 1994.

14 Thompson J. Difficult behaviour in drug-misusing and non-drug-misusing patients in general practice - a comparison. Br J Gen Pract 2001; 51: 391-393.

15 Neville RG. Violent patients in general practice. Practitioner 1986; 230: 1105-1108.

16 Dixon CA, Tompkins CN, Allgar VL, Wright NM. Abusive behaviour experienced by primary care receptionists: a cross-sectional survey. Fam Pract 2004; 21: 137-139.

17 We don't have to take this. Managing violence in mental health. Resource sheet update. UK Department of Health, 2002. Available at: http:// www.nhs.uk/zerotolerance/mental (accessed Sep 2005).

18 Naish J, Carter YH, Gray RW, et al. Brief encounters of aggression and violence in primary care: a team approach to coping strategies. Fam Pract 2002; 19: 504-510.

19 Sims G, Bolton P. The supply and distribution of general practitioners. In: General practice in Australia: 2004. Canberra: Australian Government Department of Health and Ageing, 2005.

20 Hobbs FD. General practitioners' changes to practice due to aggression at work. Fam Pract 1994; 11: 75-79.

(Received 2 Aug 2005, accepted 28 Aug 2005) 